Essay

\title{
Speaking Volumes: Studying Depth in Holographic Narratives
}

\author{
Doris Vila \\ Independent Researcher, Brooklyn, NY 11238, USA; dorvila@vilamedia.com
}

Received: 2 August 2019; Accepted: 11 December 2019; Published: 18 December 2019

check for updates

\begin{abstract}
This article investigates a decision every holographer makes: where to place light-forms along the z-axis, given the power of light imagery. This choice governs what sits behind the plate, what is on the surface and what projects in front of the plate toward the viewer. After considering ways that the placement of imagery sets the stage for viewers to respond to a holographic narrative, examples are offered from a series of reflection holograms. These examples are drawn from a continuing creative practice which explores aspects of narrative within the unique parameters of holographic volume.
\end{abstract}

Keywords: holography; hologram; luminous imaging; perception; illusion; 3-D; three dimensions

\section{Introduction: Picturing the Z-Axis}

Even forgetting high-school algebra, most people can navigate locations using the x-axis and y-axis of Descartes' coordinates. By contrast, many are less at home traveling the z-axis, especially without signposts. Holographers, however, quickly learn that the $\mathrm{z}$-axis is where the magic happens. Light imagery can attract and engage the viewer by leaping out of the frame, defying the norms of a two-dimensional picture.

In the visual arts, narrative is usually constructed as a sequence of images, where viewers extract meaning by following a line from left to right on the horizontal $x$-axis, then down the $y$-axis to the next line. In a graphic novel, for example, the page may be split into a number of panels. Narrative events may pop out of one frame into another to expand a moment or heighten dramatic effect. A hologram allows the viewer to move away from the surface: we have two options along the z-axis in addition to imaging on the surface. On one hand, we can push imagery away from the viewer, behind the framed surface; on the other, we can bring the image in front of the surface, and thus more directly toward the viewer.

A hologram may be imagined either as a phantom representational image or as an abstract volume of color. In either case, the light-form of an object gets separated from its concrete material origin via a world of lasers and laboratories. The result is a weightless dimensional image that observers can see but not touch, stretching the limits of believability and provoking wonder.

While I was teaching at the School of the Art Institute of Chicago in the 1980s, I took a group of my students to the Chicago Holography Museum ${ }^{1}$ run by one-time ice-skating champion Loren Billings. Afterwards in class, one student said, "Holograms are so cool to look at. But if I saw an exhibit of the actual things on pedestals, I doubt that I would be impressed." That student's concern

1 Ironically, the Museum of Holography was housed in a former coffin factory and offered a lugubriously elegant exhibition space in the forgotten West Loop, soon to acquire reflected glory from Oprah Winfrey starting her media empire across the street. Some accomplished holographers worked in the basement there, notably Ed Wesly, Doug Tyler, Melissa Crenshaw, Larry Lieberman, Steve Smith and Rick Bruck. 
led me to question what was compelling about creating a light-form to represent an object. In a way, holography reminded me of synecdoche - the way language works when a word stands in for a physical item (Eco 1995).

I became curious about how words inhabit the transitional border between thought and matter, especially when meaning radiates in other than straight lines. I studied charts, maps and diagrams, where the reader roams the $\mathrm{x}$ and $\mathrm{y}$-axes, discerning fresh meaning in a personal discovery sequence. As a result, I made a series of large holograms where text and found objects float in volumes of color-non-linear narratives in a teasing relationship with science. Drawn shapes, words and shadow objects slid through each other, changing with each step and dip, as well as changes in illumination.

This work in turn led to a series of environments and performance pieces where holograms acted as focal elements in walk-through spaces. The public drove the narrative as their movement triggered changing light, video and sound. As a security guard near one of the installations remarked about holograms on slowly revolving bases, "I keep seeing new things. You got a lot of picture in the one frame."

\section{Why an Image Made of Light Is Special}

Making a hologram transforms an object into a light-form. When the light-form image floats in front of the holographic surface, which functions as a frame or window, it affects viewers in two ways:

1. The image appears closer to viewers than the frame, approaching them from the same side of the glass window.

2. The image is weightless, an apparition.

When viewers question what they perceive as a weightless apparition, they often swipe a hand through the ghost image, attempting to make sense of the experience. In some works, a physical object is aligned with a holographic phantom so the contradictory images inhabit the same space. In the seminal work The Meeting by artist Rick Silberman, the phantom bowl of a wine glass is supported by an actual broken glass stem.

The ethereal image can feel like a personal vision, compounding the feeling of mystery. In galleries, viewers often point at a holographic image to share it with a companion, only to realize that the companion does not see the same thing, and may not see anything at all, until they align their point of view or even swap places.

Psychologists Dacher Keltner and Jonathan Haidt investigate awe as a moral, spiritual and aesthetic emotion, suggesting that, "Supernatural causality-based awe-as one might experience if they saw an angel, a ghost, or a floating object-will be tinted with an 'element of the uncanny,' which can be terrifying or glorious depending on the source" (Keltner and Haidt 2003).

Because the holographic image is a floating object built of light, the potential awe-effect on the viewer deepens. In 1972, in the early days of display holography, Robert Schinella's hologram of a life-sized hand dangling jewels reached out of a store window at the Cartier Fifth Avenue flagship. Crowds and news crews gathered. One passerby even swung at the image with an umbrella, calling it "the devil's work" (Marion 1974).

When the hologram converts matter into a glowing object, it seems to satisfy the itch to share beliefs, as if a viewer were to inhabit a waking dream that can be experienced by others. As Rudolf Arnheim wrote of Rembrandt van Rijn's work:

When the source of light is located inside the picture, the meaning changes. Now the life-giving energy establishes the center and the range of a narrow world. Nothing exists beyond the corners to which the rays reach.

Light seems to originate within the object at an indefinite distance from the observer... The indefiniteness of the outer surface endows his glowing objects with a transfigured, immaterial quality. (Arnheim 1954) 
Light effects similar to what Arnheim describes are woven into holograms. Of necessity, the image glows, drawing our attention to the light. Light is especially captivating in the third dimension, perhaps because viewers focus along the z-axis as the image appears to approach them. The power of the luminous object opens the door to visual representation of abstract ideas. In Jorge Luis Borges' The Aleph, the narrator recounts an instant of time when encountering a luminous entity:

I saw a small iridescent sphere of almost unbearable brilliance. At first I thought it was revolving; then I realized that this movement was an illusion created by the dizzying world it bounded. The Aleph's diameter was probably little more than an inch, but all space was there, actual and undiminished. Each thing (a mirror's face, let us say) was infinite, since I distinctly saw it from every angle of the universe. (Borges 1973)

Hologram viewers are primed for the narrative power of a light-form, especially when that light-form defies logic floating in front of the surface on the z-axis-it is as if they see the world in a grain of sand.

\section{Image Plane Location in the Lab}

One of the basic decisions when making a hologram is where to locate the recording film in relation to the object or imagery being captured. The physical boundary of the holographic film-plane can define three zones where imagery will appear:

1. Behind the plate;

2. At the film plane;

3. Hovering in front, projecting into the viewers' space.

Rosemary Jackson, founding Director of New York's Museum of Holography, summarized the technical terms for the viewer's experience:

A holographic image can project in front of the plate (a real image), in back of the plate (a virtual image), or it can straddle the plate (an image plane). (Jackson 1976)

We will examine these zones one at a time, considering spatial location as it affects how viewers perceive narrative in each area.

\section{Behind the Plate}

Trapped behind the holographic plate, we find a territory already familiar from wunderkammers, dioramas, Cornell boxes ${ }^{2}$, stage sets and the science of perspective. Governed by the right-reading orthoscopic image, its volume obeys all the viewing rules of the world outside the hologram as if looking at a scene through a window or into a box from the position of the voyeur. By locating the imagery behind the film plane, the holographer grounds the recorded scene with an air of authority. The scene behind the plate reflects a moment in that past that has since disappeared. Viewers peek into a window at a space they can never enter and never touch, as if it were a memory.

\section{At the Film Plane}

When imagery is located on the surface of the recording medium, the hologram takes on a one-to-one correspondence with the world. For one spatial instant, it acts like a photographic plate. In a photograph, the camera lens works by matching each point of reflected light with a point of light on the film (or recording sensor). Although the camera lens re-forms the external image upside down

2 A highly innovative artist, Joseph Cornell collaged printed ephemera and found objects into lyrical box constructions. His work and related documentation are archived at the Joseph Cornell Study Center of the Smithsonian American Art Museum, Washington, DC. https://americanart.si.edu/artist/joseph-cornell-995. 
and backwards, the image is re-flipped into right-side-up and left-right-correct viewing when printed, paralleling the way our brains flip the inverted images that land on our retinas.

In holography, the plate itself becomes many lenses, so we get the added bonus of the pseudoscopic image, not just upside-down and backwards, but also inside-out-a swimmy mold of the recorded scene (Abramson 1981). Holographers juggle technical tricks of the trade by illuminating the plate to study the virtual or real-looking image and then flipping the plate around to see the pseudoscopic image. One dot of laser light on a master hologram of, say, a face re-creates a sharp image from a single point of view to guide positioning for $\mathrm{x}$ and $\mathrm{y}$ framing. When holographers illuminate an entire master plate, the sharp one-point image turns to blurry soupiness from the scattered light of many points of view merging and seen simultaneously.

At first glance, this haze of the "real image" is a fuzzy mess, although optics terms this haze of light as "real" because the light is a focusable projection. As the holographer moves a white card parallel to a master plate closer and then farther along the z-axis, we can hunt for the focus of, say, a nose, then back away an inch or two to where the eye is in focus, then move the card farther back and hunt for an earlobe. If we put the image-plane at where the eye is in focus, that eye will be bound to the film plane, with the nose poking through the plate.

\section{Hovering in Front}

Here, light takes on its own form in front of the holographic window, tempting viewers to reach for an image that is not physically there. They fall for the enchantment. At first, they may be disoriented, but then they often are delighted that they cannot touch what they can clearly see.

It can be elusive to judge how far an image intrudes into the viewing space. It is as if tape measures were abandoned at the image plane. What feels like an inch can turn out to be 4 " or 5 " when measured, likely because the light wavefront reconstructing the hologram may curve differently from the recording wavefront. It is similar to projecting a picture onto the surface of a balloon and then the viewer stepping inside the balloon to see it. This difference in the wavefront may also make the image appear to swing as the viewer moves from side to side to see the depth of the imagery. Imagery in front of the plate appears to slide away from the direction the viewer is moving. As the viewer moves right, the projection appears to move left. Thus, grabbing at the image leaves the viewer with an empty hand.

Both holographers and stereo photographers often avoid the edges of the plate for front-projecting imagery. At the edge, an object floating in front of the window appears to collapse back on to the film plane, tethering the 3-D to the two-dimensional frame. The projected image seems to need air around it to lift it away from the surface. Curiously enough, it appears that this knowledge has not passed to 3-D moviemakers, so we can find many cases where the frontal projection takes on an invisible convex screen on which the sides of a flurry of particles in motion seem to curve away from the viewers' eyes. For example, as the bats swarm in Batman, the 3-D effect is most pronounced at the center, well away from the edges of the screen.

It can be tempting to dazzle viewers with tech wizardry by launching imagery as far as possible off the film plane toward the viewer. However, experience teaches holographers that defining the edges with focus enhances viewers' depth perception.

\section{Narrative}

Holographic artist Jacques Desbiens states that "Linear narration is shattered in holography" (Desbiens 2019). The holographic artist may choose to resist the tyranny of one-point perspective. The artist may resign as "dictator of a single viewpoint" and accept the challenge to become a "framer of possible views". My work embraces this role, leading me to make holograms of ideas instead of things. The author shares a space with viewers. They may combine story elements again and again to yield fresh lines of personal meaning and narrative. By thinking of the hologram as a mirror with a memory, I want to encourage an intimate dialog with narrative depth. With these z-axis thoughts in mind, I worked on three reflection holograms. 
There are three women in this hologram, one in each of the three zones for $\mathrm{z}$-axis placement discussed below (Figure 1):

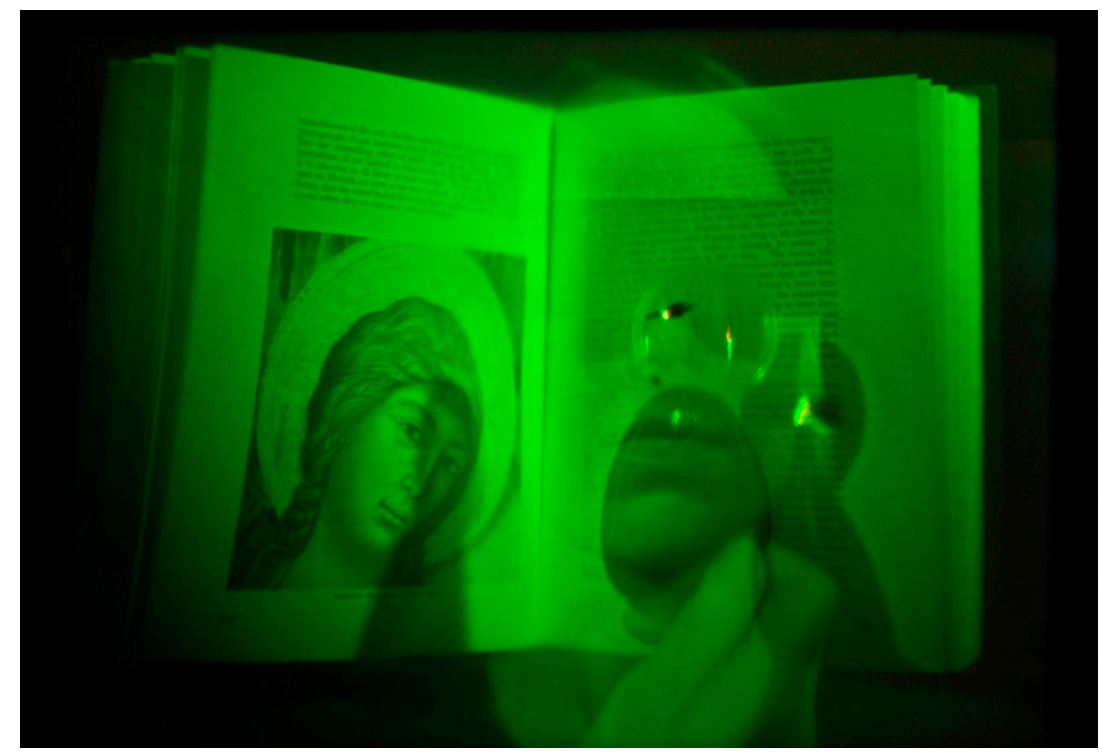

Figure 1. Speaking Volumes, reflection hologram, 2001, $20 \mathrm{~cm} \mathrm{H} \times 25 \mathrm{~cm} \mathrm{~W}$, created by author.

Behind the film plane, on the left, grounded in history, an academic view of Madonna in an art book, an idealized woman enshrined for viewing and study, a relic of the past, recalling imposed beliefs and modeling subservient behavior for women.

At the film surface, on the right, the historical image is matched with the living ghost of a woman's face, inhabiting the right-hand pages with her eyes masked. She is visible but is blinded, trapped in the present moment, looming out of the page.

In front of the film plane, the hand of a third woman holds up a magnifying glass that casts a shadow on the Madonna. We see only her hand, but we can peer through the lens, suggesting her careful examination of how the canon served to determine and accordingly oppress the space occupied by this idealized woman.

In Open book (reading between the lines), (Figure 2) a pair of holographic plates are mounted in one frame tilted slightly toward each other, like pages of an open book. On the left "page", shredded paper bits are suspended in all three zones of the z-axis, around and inside the baby's head which also occupies the 3 zones, slightly behind the film surface, through the surface and out in front of the plate. The mother lifts her child up into the cloud of floating pieces. The position of her fingers curving in front of the plate echoes the edges of the pages falling on the right side of the diptych.

On the right "page", drops of milk fall in lines just behind the film plane at the top, then on through the pages of an atlas until, at the bottom, they fade floating in front of the frame, approaching the viewer as they fall out of sight. The milk raining through pages of an atlas alludes to ancient searches for a nourishing home in dry terrain. 


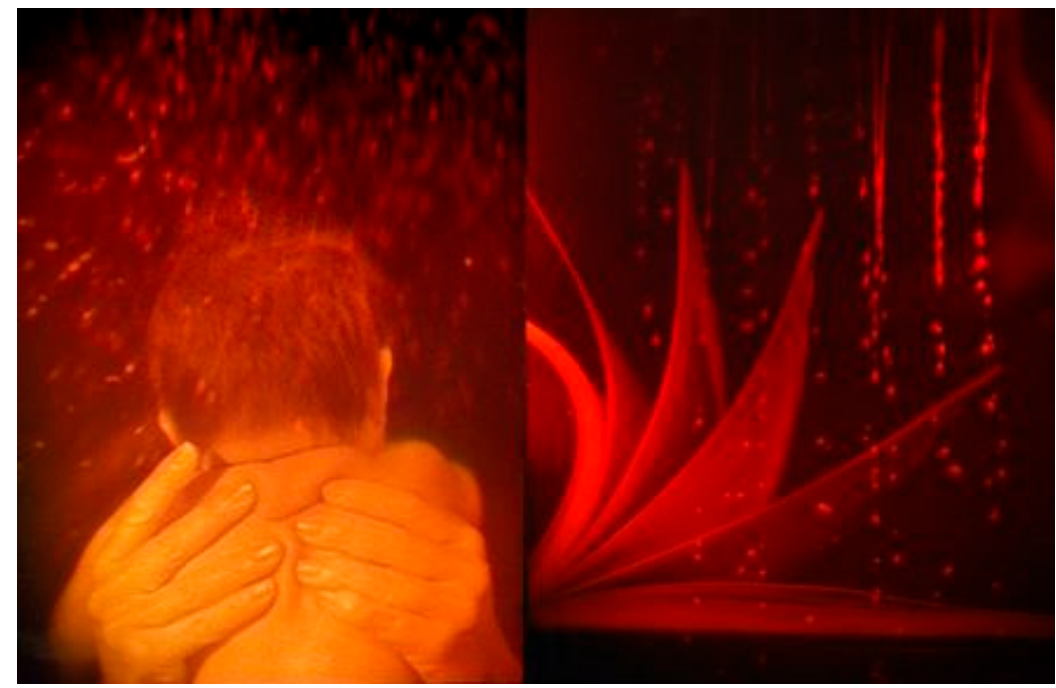

Figure 2. Open book (reading between the lines), reflection hologram diptych, 2001-2008, $40 \mathrm{~cm} \mathrm{H} \times 60 \mathrm{~cm}$ $\mathrm{W}$, created by author.

The hologram, A device for the lifting of gravity (again), 2008, (Figure 3) is illuminated by projected light from a security-camera feed to display live, moving imagery of viewers' feet as they walk past the installation. The three-dimensional imagery recorded in the hologram is of animated fire. The combination of the live projection and the animated holographic image allows viewers to "walk" through fire, reminiscent of medieval trials of witches and saints walking through a bed of red-hot coals. The real-time video of the viewer's feet anchors the "now" with the flames licking just behind and in front of the plate, extending the time-based narrative into space. Viewers recognize their feet almost instantly, often commenting "that's me" at the image of their feet lifted to face them at eye level. They scuff their feet and then turn away, looking over their shoulders to make sure their feet follow them. One viewer even searched for the camera at the floor level in order to rub hands together to pretend-warm them in the phantom flames. Such acts of viewer participation show how the spatial flux initiated by a hologram encourages a narrative response.

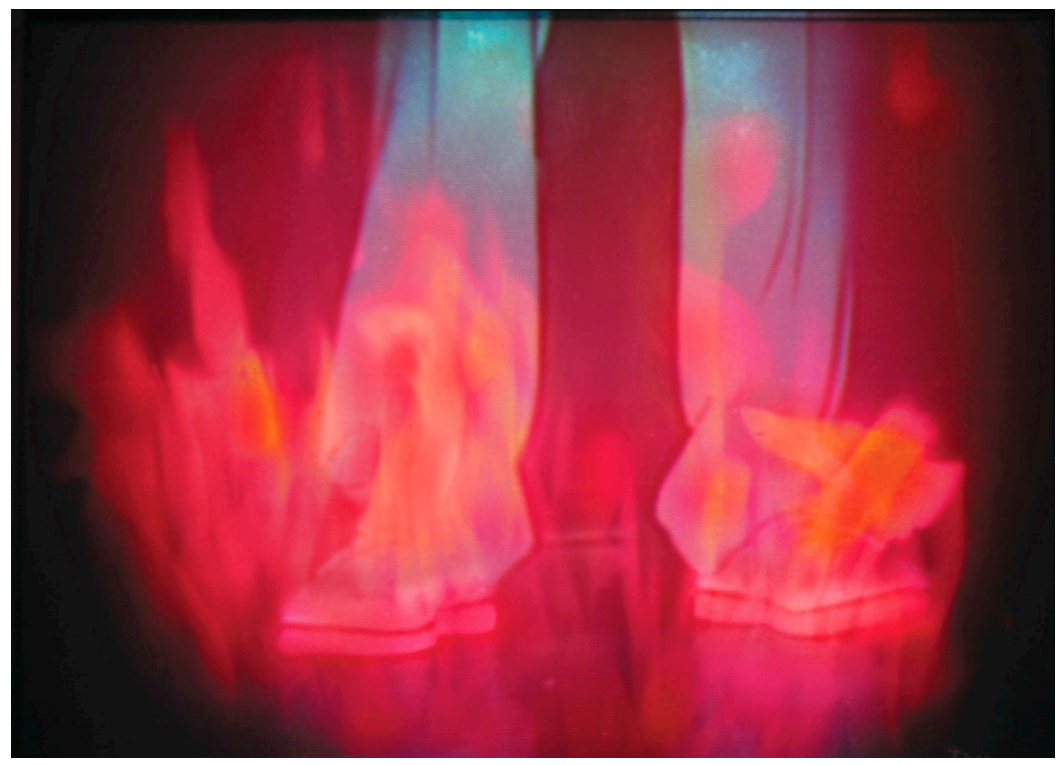

Figure 3. A device for the lifting of gravity (again), 2008, reflection hologram $30 \mathrm{~cm} \mathrm{H} \times 40 \mathrm{~cm} \mathrm{~W}$, video projection of live security camera, used by permission of David Licht. 


\section{Observations}

I began my quest for narratives in holographic space with big charts, maps, and diagrams of pseudo-scientific phenomena floating in volumes of color. The large holograms and installations enveloped the peripheral vision of viewers with the power of scale. In the three works illustrated here, I seek to fill the holographic space with deliberate, contemplative content on an intimate scale. These works draw on a sensitivity to light in the third dimension to evoke past and present, reaching out for engagement on the z-axis toward the eye of the beholder.

\section{Conclusions}

At first glance, z-axis decisions may appear to be matters of technique. In practice, however, the holographic plate serves as a boundary with strong narrative potential. A scene with objects set behind the plate evokes distance as being in the past-beyond the reach of viewer influence. Imagery at the plate itself approaches a photographic context, corresponding point-to-point with the world. Sandwiched between the past and future, the plate anchors the viewer in the present moment. Light-forms hovering in front of the holographic plate escape the fixity of gravity and encourage viewer involvement. As viewers reach for the light-form, they cross a bridge to a world of fiction. Weightless 3-D images become messages in a holographic bottle. By tapping into the power that the uncanny light-form can provoke, artists may break a glass barrier between mind and possible futures. Time and timelessness are simultaneously promoted by the holographic artist, who is already shaping a range of possible narratives as the three spaces along the z-axis converse with each other.

Funding: This research paper received no external funding.

Acknowledgments: With thanks for hologram production assistance to the Center for Holographic Art, Ana Maria Nicholson, Dan Schweitzer, Sam Moree, Ikuo Nakamura, Kate Yourke, Lillian Vila Licht and David Licht. Thanks for exhibition support to Thomas Cvetkovich and the Butler Institute, Youngstown, Ohio. Thanks for editorial assistance to Gordon Pradl and Molly Gallentine.

Conflicts of Interest: The author declares no conflict of interest.

\section{References}

Abramson, Nils. 1981. The Making and Evaluation of Holograms. London: Academic Press Ltd., pp. 49-50.

Arnheim, Rudolf. 1954. Light. In Art and Visual Perception. Berkeley and Los Angeles: University of California Press, pp. 313-316, (italics supplied).

Borges, Jorge Luis. 1973. The Aleph and Other Stories, 1933-1969. Translated and Edited by Norman di Giovanni. London: Pan Books Ltd.

Desbiens, Jacques. 2019. The Dispositif of Holography. Arts 8: 28. [CrossRef]

Eco, Umberto. 1995. The Search for the Perfect Language. Translated by James Fentress. London: Blackwell Publishers, pp. 20-24.

Jackson, Rosemary. 1976. Through the Looking Glass, Catalogue of Museum of Holography exhibition.

Keltner, Dacher, and Jonathan Haidt. 2003. Approaching awe, a moral, spiritual and aesthetic emotion. Cognition and Emotion 1702: 297-314, (italics supplied). [CrossRef] [PubMed]

Marion, Jerry. 1974. Physical Science in the Modern World. New York: Academic Press, p. 519.

(C) 2019 by the author. Licensee MDPI, Basel, Switzerland. This article is an open access article distributed under the terms and conditions of the Creative Commons Attribution (CC BY) license (http://creativecommons.org/licenses/by/4.0/). 